
Encounter Health issues During the Reproductive Life

\title{
Annsofie Adolfsson ${ }^{1,2 *}$
}

${ }^{1}$ Faculty of Medicine, School of Health Sciences, Örebro University, SE-701 82 Örebro, Sweden

${ }^{2}$ Fakultet for helsevitenskap, Institutt for sykepleievitenskap - Vestfold, University College of Southeast, Norway

\section{Abstract}

The EKC model (Empathy, Knowledge and Care) provides the necessary empathy, knowledge and care for the women who encounter health issues during their reproductive life. This approach to caring requires that healthcare workers are knowledgeable in order to confirm that a patient has suffered a miscarriage or a IUFD (Intra-uterine fetus death). Through understanding and training in the EKC model the healthcare professional increases their ability to be sympathetic and empathetic to a patient's needs. The workers get training in sexual and reproductive health in order to intimately understand how they affect the lives of individuals and their families.

Sexual and reproductive health is a cross-sectional science that includes medicine, psychology, sociology and the caring sciences. Some of the more commonly experienced issues are in the areas of spontaneous abortion, miscarriages, invitrofertilization and adoption. Issues such as sexual abuse and violence towards women is another issue that is treatable with the EKC model. Pregnant women with diabetes type 1 fall under "maternity and diabetes" issues.

Intimate knowledge about how the grieving process works is essential to be able to provide the necessary support to the patient. It is possible that the support will give them the courage and motivation to try and conceive again. One key aspect of the EKC model is to provide open and clear communication between the healthcare personnel and the patient, whether that communication is done face-to-face or otherwise. The structured EKC conversation provides a viable tool to help healthcare professionals assist their patients in coming to terms and resolving their loss.

\section{Introduction}

\section{EKC Model}

The EKC model provides empathy, knowledge and care to women with their health issues during their reproductive life. This approach to caring requires that healthcare workers are knowledgeable inorder to confirm that a patient has sufferered a miscarriage or an IUFD (intra-uterine fetus death). There is research that demonstrates that when the EKC model is applied, patients feel that they have received the appropriate professional care when they needed it. The EKC model recommends meeting with the patient one or two times but more sessions can be scheduled if necessary.

\section{Theoretical}

EKC stands for Empathy, Knowledge and Care and is a model designed to assist the staff in the Swedish health care system who come in contact with women that have suffered pregnancy loss though miscarriage, missed abortion or with intra-uterine fetal death (IUFD). The EKC model is based on research and clinical application and it may be applied to both acute and primary health care. Through encounters with women who have experienced miscarriage and IUFD, personnel in maternity care are enabled to provide support to comfort patients in physically and emotionally difficult situations.

\section{Empathy}

The term Empathy is closely related with immersion, involvement and compassion. To empathize is about having a mental ability to understand and sympathize with others regardless of whether you agree or not. Having the ability to feel empathy means that you can and source are credited. experience and understand the feelings of others. Affective empathy enables the care giver to feel what the patient is feeling. Cognitive empathy enables the care giver to understand what the patient is feeling. The final component of the empathetic system is empathic accuracy, which enables the care giver to determine if the feeling is derived from the care giver or the patient. These three forms of empathy are interdependent in order for a feeling of empathy to occur.

To understand how empathy works in a real live situation we can consider the following example. The care giver who meets with a woman undergoing a miscarriage has an automatic painful response within them which is affective empathy. The care giver is able to understand that the woman is in pain because they can remember a timewhen they experienced pain on their own which is cognitive empathy. By having enough emotional awareness for the care giver to understand that it is not them that is really in pain but the woman who is in pain determines their empathic accuracy. In this case, these are the components that are involved in the empathetic system.

\section{Knowledge}

Healthcare workers must be competently knowledgeable when

"Corresponding Author: Dr. Annsofie Adolfsson, Faculty of Medicine, School of Health Sciences, Örebro University, SE-701 82 Örebro, Sweden, Tel: +46 70090 95 56; E-mail: annsofie.adolfsson@oru.se

Citation: Adolfsson A (2016) The EKC-Model Provides Empathy, Knowledge and Care for Women that Encounter Health issues During the Reproductive Life. Int J Gynecol Clin Pract 3: 121. doi: http://dx.doi.org/10.15344/2394-4986/2016/121

Copyright: (C) 2016 Adolfsson. This is an open-access article distributed under the terms of the Creative Commons Attribution License, which permits unrestricted use, distribution, and reproduction in any medium, provided the original author 
Citation: Adolfsson A, Jordmorfag I (2016) The EKC-Model Provides Empathy, Knowledge and Care for Women that Encounter Health issues During the Reproductive Life. Int J Gynecol Clin Pract 3: 121. doi: http://dx.doi.org/10.15344/2394-4986/2016/121

Page 2 of 6

working and interacting with women and their partners who are experiencing the loss of a pregnancy. Intimate knowledge regarding what happens when a patient is undergoing a miscarriage or an intra-uterine fetus death is absolutely essential and critical. With the knowledge of different symptoms, emotional reactions and necessary measures the caregiver can enable the woman in completing a miscarriage or giving birth in the optimum medical manner.

Knowledge and experience about the most suitable technical equipment and medicine such as pain management, examinations and treatment procedures enables the caregiver to provide proper treatment to the patient. This knowledge enables the caregiver to provide explanations as to what has happened, what is likely to happen and what caused it to happen in the first place. By being knowledgeable the caregiver is given the possibility of helping the patient to feel more comfortable in physically and emotionally challenging situations.

\section{Caring}

Caring is synonymous with care, custody, nursing, supervision, attention and consideration. These words give a descriptive overall picture of what caring actually is. A description of care developed at Umeå University says that caring aims to help a person to plan and implement actions relating to daily life in order to improve health and fitness, prevent illness and disease, and to restore and maintain health and fitness.

Right from the first contact with a woman who has experienced pregnancy loss it is very important that the caregiver can offer her individualized care based on her needs. When a patient is giving clear signals about specific needs that they have, the caregiver as a trained professional responds to the patient by giving empathy, the use of their specific knowledge and provides the suitable care technique.

When meeting with the patient it is important for the caregiver to be present, prepared and able to anticipate the course of action. It should be permissible for the patient and the family to show and express their emotions. The personnel also need to feel confident in their abilities and they need to be feeling and sympathetic human beings and not merely robotic in their demeanor and behavior. When patients experience a loss their emotions and minds are exposed and this makes them vulnerable. Seemingly smaller and insignificant things may have a great impact on the patient. As an example, if a member of the staff is visibly stressed, it may discourage patients to hesitate to ask for the+ simple things that they need for their comfort and care...such as a blanket if they are cold.

\section{Swanson Middle Range Caring Theory}

Swanson's Middle Range Caring Theory is an effective and sensitive guide to clinical practice with womenwho have experienced a miscarriage. The theory includes five categories of the therapeutic caring process which are maintaining belief, knowing, being with, doing for and enabling. The categories have the following definitions[1]:

Maintaining belief is defined as sustaining faith in the other's capacity to get through anevent or transition and face a future fulfillment. Maintaining belief is the basis of practical healthcare.

Knowing is defined as striving to understand an event as it has meaning in the life of the other.
Being with isdefined as being emotionally present to the other.

Doing for is defined asdoing for the other as he or she woulddo for their self if it was at all possible.

Enabling is defined asfacilitating the other's passage through lifetransitions and unfamiliar events.

The process emphasizes maintaining confidence in the ability of thewoman to survive and get through the event and at the same time appreciating her difficulty in coping. A soundrelationship between the midwife and the woman is important irrespective of how the situation develops in orderto help the woman find meaning and relevance in the unfortunate event as a valuable learning experience inher life. The woman's experience of wellbeing increases with the care given according to the theory.

\section{Sexual and Reproductive Health}

The sexual and reproductive health care needs of people is dependent upon the care giver being knowledgeable and understanding about the individual and their family, which involves aspects of their physical, emotional and psychological health and well-being.

http://www.who.int/reproductivehealth/about_us/en/

The World Health Organization (WHO) defines health as a state of complete physical, mental and social well-being and not merely the absence of disease or infirmity. Reproductive or sexual health and hygiene addresses the reproductive process, function and system at all stages of life.

\section{Material \& Method}

Sexual and reproductive health is a cross-sectional science that includes medicine, psychology, sociology and caring sciences. New internet oriented methods of obtaining reliable information include webpages andwebsites that provide systematic, specific and research based knowledge [2-4]. A number of different empirical studies have been conducted that form the basis of the knowledge and research in the development of the EKC model. The more experience, knowledge and information that healthcare workers have available to them regarding specific issues the better they are prepared to help others emotionally and physically cope with their health issues. Midwives, nurses and physicians need to have reliable sources of information and knowledge which is a good reason to develop the EKC model to encompass more and more treatment and response techniques for them.

\section{Empirical Studies}

\section{Miscarriage}

Women who become pregnant are faced with a statistical failure rate of approximately twenty percent. This means that one in five pregnancies are going to terminate without delivering a baby as a result. Pregnancy is verified by a pregnancy test or an ultrasound examination. Early miscarriage is defined as a pregnancy that terminates before week 13 . When a pregnancy terminates between week 13 and week 22 this is referred to as a miscarriage. After week 22 the termination is referred to as an Intra Uterine Fetus Death (IUFD) [5-7]. 
Citation: Adolfsson A, Jordmorfag I (2016) The EKC-Model Provides Empathy, Knowledge and Care for Women that Encounter Health issues During the Reproductive Life. Int J Gynecol Clin Pract 3: 121. doi: http://dx.doi.org/10.15344/2394-4986/2016/121

Page 3 of 6

Symptomatic bleeding may occur as follows:

- Light bleeding can be treated as a wait and see condition

- Dark bleeding could be a sign of missed abortion

- Heavy bleeding should be reacted to as an acute situation and the woman should go to the emergency clinic without delay

- Acute pain demands immediate attention

- Light bleeding and some lesser pain may occur in up to fifty percent of normal pregnancies

The cause of a miscarriage is always a major concern for the woman. Some of the more common causes are as follows:

- Chromosome defect is the major contributing factor as it is responsible for up to

- $\quad$ eighty percent of all miscarriages

- Chronic diseases such as metabolic (diabetes), endocrine (under or overactive thyroid

- conditions)

- Medications

- Obesity or malnutrition

- Immune system issues

- Uterine abnormalities

- $\quad$ Age or previous miscarriage

- Environmental factors

There are five basic types of miscarriage:

- Early miscarriage.... miscarriage that occurs before the week 13

- Complete miscarriage...all of the remains of the terminated fetus are ejected from the uterus

- Incomplete miscarriage...remains of the terminated fetus must be removed either surgically or with medication

- Missed abortion...a fetus that has expired and has not been diagnosed as terminated

- Ectopic pregnancy...where a fertilized egg has found its way into the fallopian tubes and must be removed surgically or with medication

Losing a pregnancy is an emotionally challenging event for the woman in particular but it can have some effect on their partner or other family members[8-10]. Some emotional reactions that woman may experience after a miscarriage run the spectrum of emotional issues and include feelings of guilt and emptiness, grief and sadness, physical and emotional numbness, difficulties in sleeping and concentrating, eating and digestive disorder and of course weeping and crying. This can be a very emotionally distressing event in a woman's life who has had high expectations of giving birth to a baby and then losing those hopes and dreams. The miscarriage can also be physically demanding with the resulting pain and bleeding $[4,11,12]$.

Treatment for woman that have suffered a miscarriage is usually a matter of resolving her emotional issues and her grief. While some of the treatment may have to do with her pain and physical suffering, most of the time it is not a life endangering event. Women need to have confirmation that the miscarriage has indeed occurred and then she typically goes into a normal grief reaction which is the most important element of her post event care[7, 13-15].
Women are encouraged to mourn their loss and each woman has her own individual way of seeking resolution to this loss $[6,9]$. She is provided with oral and written information regarding the subject of miscarriage. Some women may be in need of additional counseling and emotional support depending upon their ability to cope with their loss. Typically a routine follow up visit with the midwife is standard with the EKC model. When appropriate, contraceptives may be prescribed along with advice regarding future attempts to becoming pregnant. Any abnormalities in bleeding patterns should be resolved and a pregnancy test should be administered in order to confirm that the miscarriage is complete[13-16].

\section{Women who did not take participate in Pap Smear Test Screening}

In this Swedish study, interviews were performed with women that did not participate in a Pap Smear Test that is offered to every woman in Sweden. The Pap Smear Test is a procedure where a sample of the vaginal tissue is taken in order to detect early signs of precancerous cells. The theme of the study was the women's perception of the testing procedure and administration[17].The women emphasize the importance of professional treatment that is to be administered in a respectful and sympathetic manner throughout the whole healthcare system regardless of where and when the visit was conducted. Efficient organization and clear communication would minimize the inconvenience for the women during their appointment. The study illustrates and examines the reasons why the women did not participate in the program even though they had received a notice that they had an appointment for a Pap Smear Test. There were three categories of reasons or excuses that the women identified as their reasons for not participating. The categories identified were communication, treatment and subterfuge.

Clear communication regarding the actual appointment, the purpose of the test and the actual procedure were common issues among the group of women that did not appear for the test.

The treatment aspect of their concerns were mainly about being in an environment where the rather intimate nature of the test was comfortable for them to endure.

Some of the subterfuge or reasons beneath the surface that discouraged or prevented women from keeping their appointment had to do with the women's image of their own bodies, as they must be disrobed for the procedure. Daily tasks such as children and work often made it somewhat difficult for women to keep the appointment[18].

The women who did not participate in thecervical cancer screening (CCS) program puts herself at risk by not getting early detection of precancerous cells [19].

\section{Morning Sickness during Pregnancy}

The purpose of this study was to describe pregnant Swedish women's experience of morning sickness and their experience of the support they received. Nausea during pregnancy affects about ten percent of all pregnant women. The causes of nausea and vomiting during pregnancy are unclear. The condition can lead to dehydration, electrolyte derangement, impaired organ function and lead to serious health issues or even death if left untreated. The women can be so occupied with the misery associated with her symptoms that she feels badly about not managing her relationship with her husband or 
Citation: Adolfsson A, Jordmorfag I (2016) The EKC-Model Provides Empathy, Knowledge and Care for Women that Encounter Health issues During the Reproductive Life. Int J Gynecol Clin Pract 3: 121. doi: http://dx.doi.org/10.15344/2394-4986/2016/121

Page 4 of 6

others in her intimate circle. She is only preoccupied with strategies of how to endure her symptoms. The treatment conducted today is symptomatic and is not completely satisfactory.

When it came to the professional support from the midwife the women expressed how important it was that the midwife appeared to have sympathy and compassion for them. The midwives were perceived as supportive and they confirmed to the women how intense the loneliness could be as a result of their condition. They demonstrated their support by listening and expressing their confirmation and by giving the women sound advice while discussing their condition. The women were invited to attend a support group. The advice women received from the midwife was primarily regarding their diet and the change in lifestyle. The women were advised to get plenty of rest and to eat small meals regularly. Midwives prescribed acupressure bands, acupuncture and reflexology as plausible homeopathic treatment for morning sickness. Medication for nausea and motion sickness were also recommended by the midwives.

The results of the study show that women who suffer from morning sickness during pregnancy feel a loss of control over their lives which can have a significant impact on their mental and physical health and this makes difficult for them to function normally. Feelings of isolation, loneliness and alienation are common. It is essential that midwives are attentive in order to provide the help and support that these women require[20].

\section{Obese Pregnant Women}

Being overweight and obesity as measured by the body mass index (BMI) is an increasingly problematic issue worldwide according to the World Health Organization (WHO) [1]. Women having a body mass index greater than or equal to $30 \mathrm{~kg} / \mathrm{m}^{2}$ are considered to be obese and as a consequence they run a greater risk of complications compared to women that are not obese when they become pregnant. The aim of the study was to describe obese women's experiences of being pregnant and how they felt about their encounter with the midwife in maternity care.

According to this study about pregnant obese women the midwife's most important role when meeting with the women is to inform them about the potential risks during their pregnancy. The midwife must withhold judgment regarding their being overweight. Many women living with obesity feel that they are not seen as the person that they actually are. Obese women feel that they do not conform to the societal ideal of an attractive woman because of their size and other people's prejudices regarding their obesity. When an obese woman becomes pregnant, they may feel more comfortable with their standing in society because there is a happy explanation for the size of their abdomen. They experience that they are happy and proud about their size and this gives them a sense of relief and belonging [21].

\section{Mother's Need of Support Expectations of the BVC nurse at the First Home Visit}

One of the main priorities of the child healthcare services in Sweden is a home visit by the Child Health Care (BVC) nurse to newborn babies and their parents. It is essential that the BVC nurses have a comprehensive knowledge of the parent's need of support and their expectations as new parents in order to be able to fulfill their needs. The aim of this study was to describe what type of support the mothers of infant children are in need of and what their expectations are of the BVC nurse when it is time for the home visit from the nurse.

The findings in this study found that first time mother's experienced uncertainty in their new role as a mother and caring for a baby. Parents seek support from the BVC nurse and they expect her behavior and attitude towards them to be friendly and professional. The fact that she is privy to personal knowledge of the family gives the parents a feeling of security when they contact the child healthcare center for various reasons. The mother's need for support to develop as a parent and to feel secure in the parental role was a reoccurring theme in the interviews and became the theme of the study [22].

\section{Midwife's Experiences of Using Intuition as a motivating element in conveying Assurance and Care}

The expectations of a successful outcome during childbirth are high for all of the parties concerned.The overall objective of prenatal care and birth care is that midwives contribute to create the most positive experience for the expectant parents concerning their pregnancy, the actual childbirth and the child's infancy.

The results of this analysis revealed three themes:

Organizational-professional condition: Managements' organization of the workload and how management utilized competent and experienced midwives affected the midwives' ability to contribute to a sense of security and provide competent nursing care for expectant parents.

The communicative ability of the midwives: When the communication was based on sensibility and compassion, the midwives' were enabled to create a sound and trusting relationship between themselves, at the MVC and with the expectant parents.

Thereflective emotional competence of the midwife: The emotional involvement on the part of the midwives was an essential requirement for carrying out the work in a satisfactory manner.

The participants in the interviews, generally speaking, acknowledged that they had learned to trust and depend upon their inner feeling and intuition in their work as midwives. Using this intuition as an important tool and motivating force in their craft enabled them to trust themselves and their competence in order to analyze a situation, make a decision and formulate a solution. Even with their abundance of experience, the interviewees still feel a fascination and awe with this feeling of intuition as it enables them to know what every parent and couple feels and what they need to know with regard to their experience of their pregnancy and delivery [23].

How the Health Care Nurse Supports and Enhances the Child's Attachment to Their Parents

The Child Healthcare Clinic (BVC) nurse supports and encourages the child's bonding to their parents during the regularly scheduled checkups at the healthcare clinics. Parents need to feel that they are empowered in order to encourage the child to have a healthy connection to the parents. This is accomplished by the BVC nurse building and creating a trusting relationship with the parents and providing support for them in their new roles as parents. The BVC nurses must have comprehensive knowledge about the needs 
Citation: Adolfsson A, Jordmorfag I (2016) The EKC-Model Provides Empathy, Knowledge and Care for Women that Encounter Health issues During the Reproductive Life. Int J Gynecol Clin Pract 3: 121. doi: http://dx.doi.org/10.15344/2394-4986/2016/121

Page 5 of 6

and development of children and they need to have exceptional communication skills as well. It is also mandatory that the BVC nurse have access to cooperation and support from their colleagues and the support of other related professions. Providing support to parents during the bonding period of their infant children is a most important function for BVC nurses because there is much to be determined about children's development and future possibilities during this formative period[24].

\section{The Experience of the Low Priority Patient during waiting time at an Emergency Department}

Work in the emergency department is characterized by fast and efficient medicalefforts to save lives, but it can also involve a long waiting time for patients. Patients are givena priority rating upon their arrival in the clinic based on the seriousness of their problem andnursing care for lower priority patients is given a lower prioritization. Regardless of their medicalprioritization all patients have a right to expect good nursing care while they are waiting. Thepurpose of this study was to illustrate the experience of the low prioritized patient during theirwaiting time in the emergency department.

Lower priority patients do not receive urgent attention by nursing staff. Patients reported feeling powerless, insulted, and humiliated when their care was delayed without their understanding aboutwhat was happening to them. The findings from interviews with low priority patients at the emergency clinic resulted in four different themes: being dependent on care, beingexposed, being vulnerable, and being secure. The goal of the health care provider must be to minimize and prevent suffering, to prevent feelings of vulnerability and to create conditions for optimal patient well-being [25]

\section{Adolescents with Endometriosis}

Endometriosis can have a substantial impact on the quality of life for young women suffering from the condition. The condition can be managed withappropriate support from the healthcare system. Adequate treatment can have animportant influence on improving the quality of life for young women affected by this condition.This study aims to establish the level of support youngwomen received from school health services in Sweden who were diagnosed with endometriosis duringtheir school years. Young women were found to be absent from school or missing extra-curricular activities due to pain and abnormal bleeding associated with their menstrual cycles. Some of the women thought that these symptoms were normal and did not consult the school nurse as a result of their limited experience. Others did not consult with the nurses because of a perception of poor treatment [26].

\section{Motherhood and Type 1 Diabetes (MODIAB)}

Women with type 1 diabetes face increased risks for complications in relation to childbearing such as for preeclampsia, congenital malformations, operational deliveries, perinatal mortality, fetal macrosomia and neonatal complications. During pregnancy, in order to optimize the probability of giving birth to a healthy child, the blood glucose levels of these women need to be as normal as possible. When in transition to motherhood they experience a variety of psychosocial issues such as increased levels of stress and anxiety, diabetes related guilt, a sense of disconnectedness and medicalization of pregnancy
After childbirth, they experience a 'double stress, in addition to the ordinary challenges they face as new mothers, they also need to focus on getting their blood glucose levels normal.

The unique contribution of this project is the evaluation of the effectiveness of a specially designed web-based support for mothers with type 1 diabetes, which is expected to increase the women's personal capacity, including knowledge and thereby strengthening their autonomy during pregnancy, breastfeeding and early motherhood. Web-based support systems have the potential to bridge gaps that can exist between the different health-care systems and professionals providing care during the child bearing period and especially during early motherhood. They can also offer increased convenience for users in terms of time, mobility, geography and promote equal access to qualityassured and evidence-based information.

Content and layout in the Web support were developed collaboratively by project managers, advisory and scientific reference groups, technical producers and representatives for the target group. Based on needs assessment and evidence synthesis, three main components of complementary Web-based support were identified:

Specific information about pregnancy, childbirth, and early motherhood in relation to type 1 diabetes

- A self-care diary, including a device for documenting and evaluating blood glucose

- levels, insulin doses, food intake, physical activities and overall well-being

- A forum for communication between women with type 1 diabetes in the childbearing period.

\section{Widespread Sexual Violence}

The impact of sexual violence is devastating on a woman, the family and the community. This study was conducted in North-Kivu which is in the Democratic Republic Congo. The aim of this study was to explore life experience after sexual violence. The research method was an inductive qualitative method, using phenomenology method and using individual in-depth interviews with assaulted women from the region. In Africa, violence against women begins in childhood. African families have an obvious preference for sons over daughter as African culture views sons as an asset to their family, whereas families that have only daughters are considered subpar. Young girls are even further subjected to violence by the act of female genital mutilation. Sexual violence which of course includes rape is a powerful tool in violence perpetrated against women. Much of this violence has been committed by members of the armed forces, the police and even acquaintances of the women such as friends of the family or even family members. The very men that are supposed to be protecting them are preying on them.

Women who have been subjected to this type of terrifying behavior and violence are in deep need of specific health care to bring them back to a state of being where they can function. This study is expected to give a deeper understanding of how women in North Kivu experience life after sexual violence and give to the healthcare personnel important knowledge to develop the specific health care needed. 
Citation: Adolfsson A, Jordmorfag I (2016) The EKC-Model Provides Empathy, Knowledge and Care for Women that Encounter Health issues During the Reproductive Life. Int J Gynecol Clin Pract 3: 121. doi: http://dx.doi.org/10.15344/2394-4986/2016/121

\section{Conclusion}

Besides having the surrounding health care resources each woman has their own internal ability to aid in psychological recovery. To offer the woman the best medical treatment and management plan will also help her better in understanding what has happened, why it has happened and what the potential prognosis is. One key aspect of the EKC-model is open and clear communication between the healthcare personnel and the patient, whether the communication is face-to-face or remote. The structured EKC conversation provides a viable tool to help healthcare professionals assist patients in coming to terms with their loss.

Research shows that when the EKC-model is used patients feel that they have received the proper and appropriate professional care when they needed it. The EKC-model recommends offering to meet the patient one or two times but more sessions can be scheduled as necessary $[7,14,16]$.

When coming into contact with a woman who has experienced sexual violence, miscarriage or other reproductive issues it is critical that her care is tailored to her individual needs. It is up to the health worker or team to determine what her needs are, encouraging her to express them and using their knowledge to give her the optimal care.

Through understanding and training in the EKC approach healthcare professionals increase their ability to be sympathetic and empathetic to patient's needs for care.

\section{Competing Interestes}

The authors declare that they have no competing interestes.

\section{References}

1. Swanson KM (1991) Empirical development of a middle range theory of caring. Nurs Res 40: 161-166.

2. Adolfsson A, Jansson M (2012) Prototype for Internet support of pregnan women and mothers with type 1 diabetes: focus group testing. Psychol Res Behav Manag 5: 97-103.

3. Berg M, Adolfsson A, Ranerup A, Sparud-Lundin C (2013) Person-Centered Web Support to Women with Type 1 Diabetes in Pregnancy MotherhoodThe Development Process. Diabetes Technol Ther 5: 20-25.

4. Adolfsson A, Arbhede E, Markuland E, Larsson PG, Berg M (2015) Miscarriage-Evidence Based Information for the Web and Its Development Procedure. Advances in Sexual Medicine 5: 89-110.

5. Adolfsson A, Larsson PG (2006) Cumulative incidence of previous spontaneous abortion in Sweden in 1983-2003: a register study. Acta Obstet Gynecol Scand 85: 741-747.

6. Adolfsson A, Larsson PG (2006) Translation of the short version of the Perinatal Grief Scale into Swedish. Scand J Caring Sci 20: 269-273.

7. Adolfsson A (2006) Miscarriage : women's experience and its cumulative incidence, in Linköping University medical dissertations, 939, Univ.: Linköping. p. $68 \mathrm{~s}$.

8. Adolfsson A (2010) Applying Heidegger's interpretive phenomenology to women's miscarriage experience. Psychol Res Behav Manag 3: 75-79.

9. Adolfsson A, Larsson PG (2010) Applicability of general grief theory to Swedish women's experience after early miscarriage, with factor analysis of Bonanno's taxonomy, using the Perinatal Grief Scale. Ups J Med Sci 115: 201-209.

10. Adolfsson A, Larsson PG, Wijma B, Berterö C (2004) Guilt and emptiness women's experiences of miscarriage. Health Care Women Int 25: 543-560.

11. Adolfsson A, Johansson C, Nilsson E (2012) Swedish Women's Emotional Experience of the First Trimester in a New Pregnancy after One or More Miscarriages: A Qualitative Interview Study. Advances in Sexual Medicine 2: $38-45$
12. Rosebrink M (2011) Missfall - kvinnors upplevelser av vården före, under och efter missfall, in Reproduktiv hälsa, Svenska barnmorskeförbundets konferens: Stockholm.

13. Adolfsson A (2011) Women's well-being improves after missed miscarriage with more active support and application of Swanson's Caring Theory. Psychol Res Behav Manag 4: 1-9.

14. Adolfsson A, Berterö C, Larsson PG (2006) Effect of a structured follow-up visit to a midwife on women with early miscarriage: a randomized study. Acta Obstet Gynecol Scand 85: 330-335.

15. Adolfsson A, Tullander-Tjörnstrand K, Larsson PG (2011) Decreased need for emergency services after changing management for suspected miscarriage. Acta Obstet Gynecol Scand 90: 921-923

16. Wojnar DM, Swanson KM, Adolfsson AS (2011) Confronting the inevitable: a conceptual model of miscarriage for use in clinical practice and research. Death Stud 35: 536-558.

17. Adolfsson A, Granevik K, Pålsson K (2012) The Reasons Why Women Do Not Participate in the Papsmear Screening and Testing Program in Sweden. Advances in Sexual Medicine 2: 31-37.

18. Broberg G, Strander B, Ellis J, Adolfsson A (2014) Attending cervical cancer screening, opportunities and obstacles - a qualitative study on midwives experiences telephoning non-attendees in Sweden. Scand J Public Health 42: 691-697.

19. Andrae B, Kemetli L, Sparén P, Silfverdal L, Strander B, et al. (2008) Screening-preventable cervical cancer risks: evidence from a nationwide audit in Sweden. J Natl Cancer Inst 100: 622-629.

20. Ericson H, Sunnergren M, Adolfsson A (2013) The Recollection of Morning Sickness and Their Support System as Documented by Women Post Pregnancy. Advances in Sexual Medicine 3: 65-75.

21. Adolfsson A, Andersen JF, Edgren KB (2013) Why Obese Women fee better about their "big" Condition when they are Pregnant, An Qualitative study performed in Sweden. Open Journal of Obstetrics and Gynecology 3: $544-552$.

22. Wilsson M, Adolfsson A (2011) Mother's need of support and their expectations of the BVC nurse at the first home visit - an interview study. Open Journal of Nursing 1: 51-58.

23. Olsson A, Adolfsson A (2011) Midwife's experiences of using intuitions as motivating element in conveying assurance and care. Health Sci Res. 3: 166-174.

24. Johansson AM, Landahl I, Adolfsson A (2011) How the Health Care Nurse Supports and Enhances the Child's Attachment to Their Parents. International Journal of Clinical Medicine 2: 418-428.

25. Dahlén I, Westin L, Adolfsson A (2012) Patients experiences of being a patient during the waiting time at an emergency department. Psychol Res Behav Manag 5: 1-9.

26. Bodén E, Wendel C, Adolfsson A (2013) Adolescents with endometriosis: Their experience of the school health care system in Sweden. British Journal of School Nursing 8: 81-87. 